\title{
Morfogénesis de la fase sexual de los helechos epífitos Microgramma mortoniana y Pleopeltis macrocarpa (Polypodiaceae) de la Reserva Natural Punta Lara, Buenos Aires, Argentina
}

\author{
Daniel Alejandro Gorrer ${ }^{1,2 *}$, Pedro Cayetano Berrueta ${ }^{1,2}$, Juan Pablo Ramos Giacosa ${ }^{1,2}$, \\ Gabriela Elena Giudice ${ }^{1}$ \& María Luján Luna ${ }^{1,3}$ \\ 1. Cátedra de Morfología Vegetal, Facultad de Ciencias Naturales y Museo (UNLP), Boulevard 120 y 61, 1900, La Plata, \\ Argentina; gegiudice@hotmail.com \\ 2. Consejo Nacional de Investigaciones Científicas y Técnicas (CONICET), Avda. Rivadavia 1917 - CP C1033AAJ - \\ Ciudad de Buenos Aires, Argentina; daniel.ale.gorrer@gmail.com, pedrocayetanoberrueta@gmail.com, \\ jpramosgiacosa@hotmail.com \\ 3. Comisión de Investigaciones Científicas de la Provincia de Buenos Aires (CIC-BA), Camino Gral. Belgrano y 526, \\ CP 1900, La Plata, Argentina; lujanluna@fcnym.unlp.edu.ar \\ * Correspondencia
}

Recibido 23-V-2018. Corregido 28-V-2018. Aceptado 27-VI-2018.

\begin{abstract}
Sexual morphogenesis phase of the epiphytic ferns Microgramma mortoniana and Pleopeltis macrocarpa (Polypodiaceae) from Punta Lara Natural Reserve, Buenos Aires, Argentina. The Punta Lara Natural Reserve is located on the riverside of the La Plata River in the province of Buenos Aires, Argentina. It is the Southernmost relict in the world of subtropical riparian forest. The epiphytic ferns studied in this work belong to the Polypodiaceae family: Microgramma mortoniana and Pleopeltis macrocarpa. Plant communities are subject to high levels of anthropization and introduction of exotic species. The goals of this work are to provide information on the morphogenesis of epiphytic gametophytes and to extend knowledge of their life cycles, contributing to their conservation. Sowing was carried out in Dyer medium. In both species the spores are monolete, ellipsoidal, yellowish and with verrucate sculpture. The equatorial diameter is $60-61 \mu \mathrm{m}$, the polar diameter is $39-42 \mu \mathrm{m}$. The germination is the Vittaria type; in M. mortoniana occurs at 20 days, while in $P$. macrocarpa occurs at six days. The filaments are uniseriate of 3-6 cells in length. The gametophyte development is Drynaria type. The cordated form is given after 40 days. In M. mortoniana, buds originated after 40 days. In P. macrocarpa, after 120 days, clathrate trichomes scale-like appear mainly on the margins of the gametophyte. The gametangia are typical of leptosporangiate ferns. The sporophyte of M. mortoniana emerged after 120 days and that of $P$. macrocarpa arose after 500 days, its blades are simple, spatulate and unicellular and multicellular branching hairs were observed. The germination pattern, gametophyte development, the presence of a lipid globule in the prothalic cell and the formation of unicellular capitated hairs are relevant characters that could be considered for systematic group. The delay in the formation of sporophytes through sexual reproduction, allows us to infer that the success of their establishment in situ would be given by the vegetative reproduction through creeping rhizomes and buds of gametophytes. Rev. Biol. Trop. 66(3): 1078-1089. Epub 2018 September 01.
\end{abstract}

Keys words: development; epiphytes; ferns; gametophyte; in vitro culture; propagation.

La reserva Integral Natural Punta Lara $\left(34^{\circ} 47^{\prime} 33^{\prime \prime} \mathrm{S}-58^{\circ} 0\right.$ '28.32" W) se encuentra ubicada en la provincia de Buenos Aires, la más poblada e industrializada de Argentina, sobre la ribera del Río de La Plata, a $12 \mathrm{~km}$ al norte de la ciudad de La Plata. Cuenta con unas 6000 hectáreas y $8 \mathrm{~km}$ de costa, donde se desarrollan distintos ambientes que albergan, entre otras comunidades, varios parches de selva en galería. Éstos representan el relicto más austral del mundo de bosque ribereño subtropical, con una flora única para la región. Actualmente, esta área protegida es considerada Reserva de Biosfera en el marco del 
Programa MAB de la UNESCO (Barbetti, 2008). Desde el punto de vista fitogeográfico, esta reserva se encuentra incluida en el Distrito Pampeano Oriental, dentro de la Provincia Pampeana en el Dominio Chaqueño (Cabrera, 1976). El bosque marginal, desarrollado sobre albardones bordeados por pequeños arroyos que entran desde el Río de La Plata, está representado por un nivel superior arbóreo y por debajo los estratos arbustivos y herbáceos, de los cuales los helechos y licofitas forman parte fundamental. En la reserva se registran 24 especies de helechos que se desarrollan sobre el sustrato o sobre troncos de árboles caídos (Giudice, Ramos Giacosa, Luna, Yáñez, \& de la Sota, 2011a).

Las comunidades vegetales de esta región se modifican no solo debido a la actividad antrópica, sino también a la introducción de especies exóticas. En las últimas décadas se ha registrado en el área protegida el ingreso de especies exóticas, entre ellas Ligustrum lucidum W. T. Aiton, Rubus ulmifolius Schott, Iris pseudoacorus L. y Lonicera japonica Thunb., lo cual sumado a la recolección y/o extracción furtiva de especies nativas de interés ornamental representan una amenaza para las poblaciones naturales que crecen en la zona (Giudice et al., 2011b). En respuesta a estas problemáticas, integrantes del Laboratorio Morfología Vegetal (FCNyM, UNLP), desarrollan desde el 2006 proyectos de conservación que contemplan estudios de cultivo in vitro y la obtención de individuos para el fortalecimiento de poblaciones (Ramos Giacosa, Giudice, Pipo, \& Luna, 2014; Luna et al., 2016; Ramos Giacosa, Gorrer, Giudice, \& Luna, 2017).

El cultivo de esporas no solo permite la producción de plantas sino que también proporciona datos de las diferentes etapas de desarrollo gametofítico y esporofítico que pueden ser significativas en estudios sistemáticos, filogenéticos y ecológicos. Conocer la autoecología de la especie es un factor importante para establecer los protocolos de conservación (Ibars \& Estrelles, 2012).

La familia Polypodiaceae cuenta con aproximadamente 12 géneros y 48 especies en la
Argentina (Zuloaga \& Belgrano, 2016), entre los cuales se encuentran los géneros Microgramma C. Presl y Pleopeltis Humb. \& Bonpl. Ex Willd. que se caracterizan por ser plantas epífitas, con rizomas rastreros escamosos, de gran longitud y soros circulares.

Microgramma mortoniana de la Sota presenta escamas no clatradas, láminas dimorfas y parafisos no peltados. Esta especie crece en Uruguay, Paraguay, sur de Brasil y en Argentina se distribuye en las selvas de las Yungas y en galería del litoral, teniendo su límite más austral en la provincia de Buenos Aires (Cacharini \& Martínez, 2016a).

Pleopeltis macrocarpa (Bory ex Willd) Kaulf. presenta escamas clatradas peltadas, láminas monomorfas y parafisos peltados. Se distribuye a lo largo del Neotrópico, África, Madagascar e India; en Argentina se encuentra en la selva montana de las Yungas en las provincias del norte y en selvas en galería en la región Paranaense, llegando hasta la provincia de Buenos Aires, su límite más austral (Cacharini \& Martínez, 2016b).

Entre los caracteres que se tienen en cuenta en el cultivo in vitro está el patrón de germinación, estudiado por Arroyo-Alfaro, PeláezPeláez \& Rodríguez-Rodríguez (2007) para Microgramma percussa (Cav.) de la Sota y para las especies mexicanas de Pleopeltis fue estudiado por Reyes-Jaramillo, Pérez-García \& Mendoza-Ruiz (2003).

El tiempo de germinación es otro carácter que analizaron Mendoza-Ruiz \& Pérez-García (2005) para diversas especies mexicanas de Microgramma. A su vez, Nayar \& Kaur (1971) estudiaron, entre otros caracteres, el patrón de desarrollo protálico de diversos géneros y especies de la familia Polypodiaceae.

Los objetivos de este trabajo son proporcionar información sobre la morfogénesis de gametofitos epífitos y ampliar el conocimiento sobre el ciclo de vida de las especies para contribuir a su conservación. Así como el adquirir herramientas que permitan implementar acciones para el fortalecimiento de poblaciones vulnerables y restauración de ambientes naturales. 


\section{MATERIALES Y MÉTODOS}

Recolección del material: Se recolectaron 5 a 6 hojas fértiles de distintos individuos de ambas especies durante marzo y abril de 2016 y 2017. Las hojas fértiles se guardaron en sobres de papel, fueron expuestas al calor emitido por una lámpara de $40 \mathrm{~W}$ durante $72 \mathrm{~h}$, para promover la dehiscencia de los esporangios y liberar las esporas. Las recolectas se realizaron en 3 parches de selva dentro de la reserva: Puesto "El Che" (3447'24.58" S \& 58 1'29.17" W), Canal Baldovinos (3445'58.74" S \& $\left.58^{\circ} 5^{\prime} 2.95^{\prime \prime} \mathrm{W}\right)$ y Puesto Base (3447'24.24” S \& 57०59'57.13” W).

Siembra: Una vez que se obtuvieron las esporas, se separaron del resto del material usando tamices de $88 \mu \mathrm{m}$ de diámetro. Para los cultivos in vitro, las esporas se esterilizaron con $\mathrm{NaClO} 10 \%$ durante dos minutos y lavaron con agua destilada. La siembra se realizó en placas de Petri de cinco centímetros de diámetro previamente esterilizadas en autoclave (20 minutos, una atmósfera de presión, $120{ }^{\circ} \mathrm{C}$ ). El medio de cultivo usado fue Dyer (1979). Se prepararon 15 cápsulas por especie y se mantuvieron bajo condiciones controladas, con un fotoperiodo de 12 horas bajo iluminación de luces LED de $28 \mu \mathrm{mol} \mathrm{m}-2 \mathrm{~s}-1$ a $22 \pm 2{ }^{\circ} \mathrm{C}$. Tres días después de la siembra se realizó el primer control, los demás controles se realizaron semanalmente (entre cinco y seis días). Se realizaron observaciones con microscopio óptico Nikon E200 y estereoscópico Nikon SMZ1000. Para determinar el porcentaje de germinación, se utilizó una cuadricula de 0.5 $\mathrm{cm}^{2}$, en la cual se escogieron tres cuadrantes al azar. Por cuadrante se contabilizó un promedio de 24 esporas sembradas. Se consideró como germinada toda espora que mostró la emergencia del primer rizoide. Los tipos de germinación y de desarrollo del gametofito se determinaron según lo propuesto por Nayar \& Kaur (1971).

\section{RESULTADOS}

Observaciones de campo: Las poblaciones de esporofitos de $M$. mortoniana crecen sobre diversas especies arbóreas con alta exposición al sol (Fig. 1A) y sobre estructuras de soporte como troncos caídos o pasarelas con menor exposición a la radiación solar (Fig. 1B). En contraste, las de P. macrocarpa crecen habitualmente sobre algunas especies arbóreas como Terminalia australis Cambess, Erythrina crista-galli L. y Puteria salicifolia (Spreng.) Radlk. a diversas alturas y sin exposición directa al sol (Fig. 1C y Fig. 1D). Estas especies no crecen bajo sombreado intenso, principalmente el generado por el denso dosel de especies arbóreas exóticas como L. lucidum.

Esporas: En las dos especies son monolete, de color amarillento, elipsoidales en vista polar y en vista ecuatorial la cara proximal es plana-cóncava y la cara distal convexa. La ornamentación es verrucosa (Fig. 2A y Fig. 3A) y está determinada por el exosporio, en tanto que el perisporio es delgado y tapiza toda la superficie. En M. mortoniana el diámetro ecuatorial es de 54.24 (61.44) $73.50 \mu \mathrm{m}$, diámetro polar de 33.25 (39.09) $45.50 \mu \mathrm{m}$ y lesura de 28 (36.47) $45.50 \mu \mathrm{m}$ de longitud. El diámetro ecuatorial de las esporas de $P$. macrocarpa es de $52.50(60.60) 68.25 \mu \mathrm{m}$, diámetro polar de 33.25 (42.08) $49 \mu \mathrm{m}$ y la longitud de la lesura es de 28 (35.74) $45.50 \mu \mathrm{m}$.

Germinación: En M. mortoniana se ocurrió a los 20 días y transcurridos los 40 días, alcanzó el $85 \%$ de germinación. En P. macrocarpa, ocurrió a los seis días posteriores a la siembra y a los ocho días ya se registró un 100 $\%$ de esporas germinadas.

En ambos casos, el rizoide se caracterizó por ser de color pardo oscuro, largo y unicelular, la célula protálica estaba constituida por un gran glóbulo lipídico en su interior que perduró hasta la fase laminar. (Fig. 2B y Fig. 3B). 

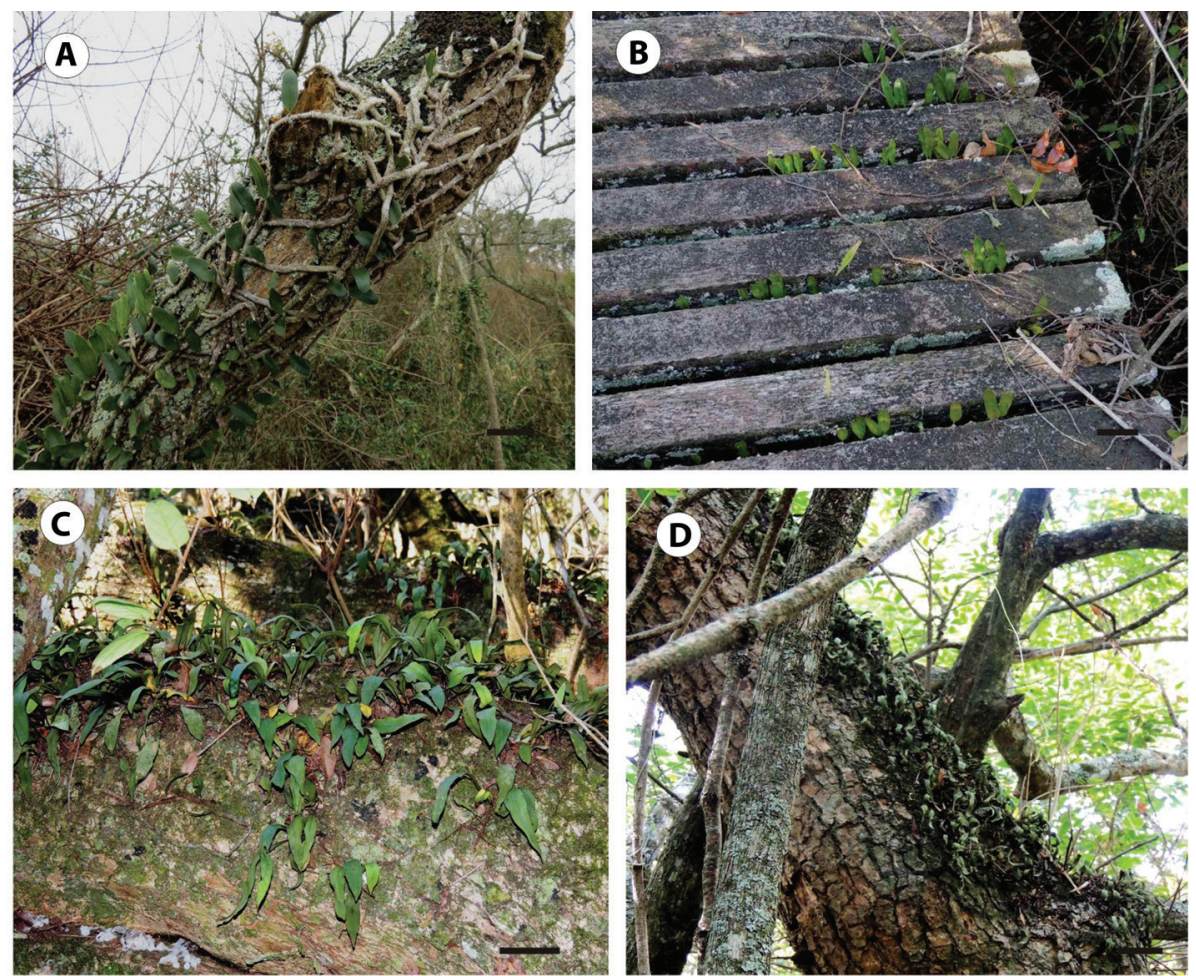

Fig. 1. Hábitat de Microgramma mortoniana y Pleopeltis macrocarpa en la Reserva Natural Punta Lara. (A) M. mortoniana sobre tronco en pie de Erythrina. (B) M. mortoniana sobre pasarela. (C) P. macrocarpa sobre tronco caído de Pouteria. (D) P. macrocarpa sobre tronco en pie de Terminalia. Escalas de las barras: A-B: $5 \mathrm{~cm}$; C-D: $10 \mathrm{~cm}$.

Fig. 1. Habitat of Microgramma mortoniana and Pleopeltis macrocarpa in Punta Lara Natural Reserve. (A) M. mortoniana on trunk in standing of Erythrina. (B) M. mortoniana on runway. (C) P. macrocarpa on trunk fallen of Pouteria. (D) P. macrocarpa on trunk standing of Terminalia. Scales bars: A-B: $5 \mathrm{~cm}$; C-D: $10 \mathrm{~cm}$.

Fase filamentosa: El filamento de $M$. mortoniana estaba conformado por 4-6 células (Fig. 2C) y el de P. macrocarpa por 3-5 células de longitud (Fig. 3C); en ambas especies fue uniseriado, con células en forma de barril y abundantes cloroplastos. Se presentaron entre los 27-35 días para la primera especie y entre los 8-15 días para la segunda.

Fase laminar: En M. mortoniana, esta fase se presentó a los 35 días (Fig. 2D y Fig. 2F), y en P. macrocarpa a los 15 días (Fig. 3D y Fig. 3E). En ambos casos se observó un gametofito espatulado con 1-2 pelos unicelulares cercanos a la zona meristemática. La cubierta de la espora persistió hasta fases avanzadas (Fig. 2F y Fig. 3F).
Fase adulta: A partir de los 40 días se observó en ambas especies la forma cordada, con dos alas bien desarrolladas, simétricas, con la zona meristemática ubicada en la escotadura (Fig. 2G, Fig. 2H, Fig. 3F y Fig. 3G) y pelos unicelulares en el margen (Fig. 2E y Fig. 3H).

En M. mortoniana, después de los 40 días se originaron yemas sobre el margen y el tejido del gametofito circundante a las yemas se necrosó (Fig. 4D). Posteriormente, las yemas formaron rizoides y tomaron una forma acorazonada similar al gametofito del cual surgieron, con un menor tamaño que éste. Estas yemas se desarrollaron en el gametofito madre y dieron origen a los anteridios. En P. macrocarpa, a partir de los 120 días se observaron tricomas 

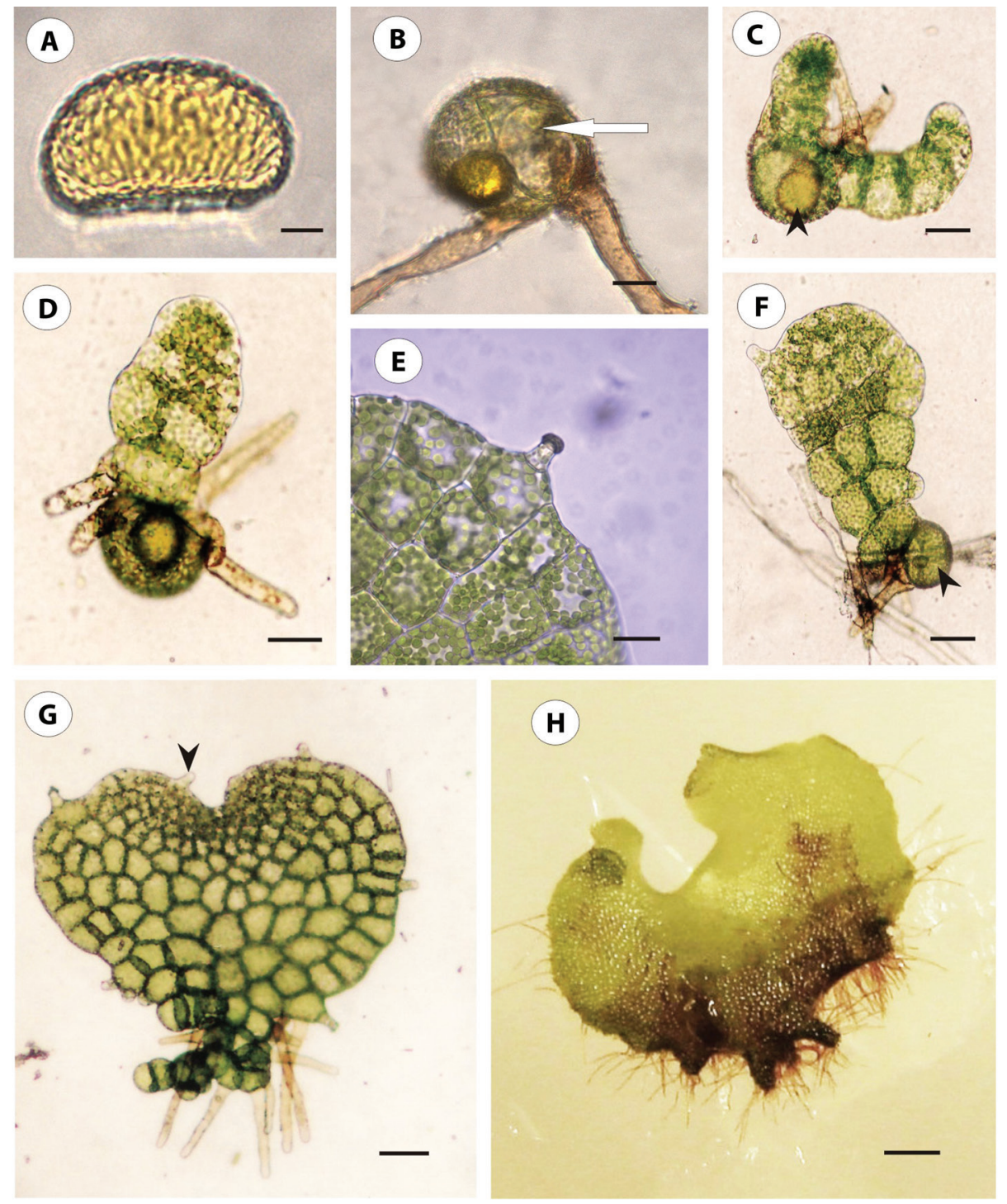

Fig. 2. Espora y gametofito de M. mortoniana (A) Espora monolete con ornamentación verrucosa. (B) Espora germinada con rizoide y célula protálica (flecha). (C) Filamentos uniseriados de 4-6 células con glóbulo lipídico en la célula protálica (cabeza de flecha). (D) Fase espatulada incipiente. (E) Detalle de pelo unicelular. (F) Fase espatulada bien desarrollada con la cubierta de la espora (cabeza de flecha). (G) Gametofito cordado joven con pelos en el margen (cabeza de flecha). (H) Gametofito cordiforme bien desarrollado. Escalas de las barras: A: $10 \mu \mathrm{m} ; \mathbf{B}: 15 \mu \mathrm{m} ; \mathbf{C}-\mathbf{E}: 30 \mu \mathrm{m} ; \mathbf{F}: 40 \mu \mathrm{m} ; \mathbf{G}: 80 \mu \mathrm{m}$; H: $250 \mu \mathrm{m}$.

Fig. 2. Spore and gametophyte of M. mortoniana. (A) Monolete spore with verrucate ornamentation. (B) Germinated spore with rhizoid and prothalic cell (arrow). (C) uniseriate filaments of 4-6 cells with lipid globule in the prothalic cell (arrowhead). (D) Incipient spatulate phase. (E) Detail of unicellular hair. (F) Well developed spatulate phase with the spore cover (arrowhead). (G) Young cordated gametophyte with hairs on the margin (arrowhead). (H) Well developed cordated gametophyte. Scale bars: A: $10 \mu \mathrm{m}$; B: $15 \mu \mathrm{m}$; C-E: $30 \mu \mathrm{m}$; F: $40 \mu \mathrm{m}$; G: $80 \mu \mathrm{m}$; H: $250 \mu \mathrm{m}$. 



Fig. 3. Espora y gametofito de Pleopeltis macrocarpa. (A) Espora monolete con ornamentación verrucosa. (B) Espora germinada con rizoide y célula protálica (cabeza de flecha). (C) filamento uniseriado de 5 células con glóbulo lipídico en la célula protálica (flecha). (D) Fase espatulada incipiente. (E) Fase espatulada bien desarrollada. (F) Gametofito cordado incipiente con pelos unicelulares (cabeza de flecha) y cubierta de la espora (flecha). (G) Gametofito cordiforme bien desarrollado. (H) Detalle de pelo unicelular. Escalas de las barras: A: $10 \mu \mathrm{m}$; B-D: $30 \mu \mathrm{m}$; E-F: $60 \mu \mathrm{m}$; G: $100 \mu \mathrm{m}$; H: $15 \mu \mathrm{m}$. Fig. 3. Spore and gametophyte of Pleopeltis macrocarpa. (A) Monolete spore with verrucate ornamentation. (B) Germinated spore with rhizoid and prothalic cell (arrowhead). (C) uniseriate filament of 5 cells with lipid globule in the prothalic cell (arrow). (D) Incipient spatulate phase. (E) Well developed spatulated phase. (F) Incipient cordated gametophyte with unicellular hairs (arrowhead) and spore cover (arrow). (G) Well developed cordiform gametophyte. (H) Detail of unicellular hair. Scale bars: A: $10 \mu \mathrm{m}$; B-D: $30 \mu \mathrm{m}$; E-F: $60 \mu \mathrm{m}$; G: $100 \mu \mathrm{m}$; H: $15 \mu \mathrm{m}$. 

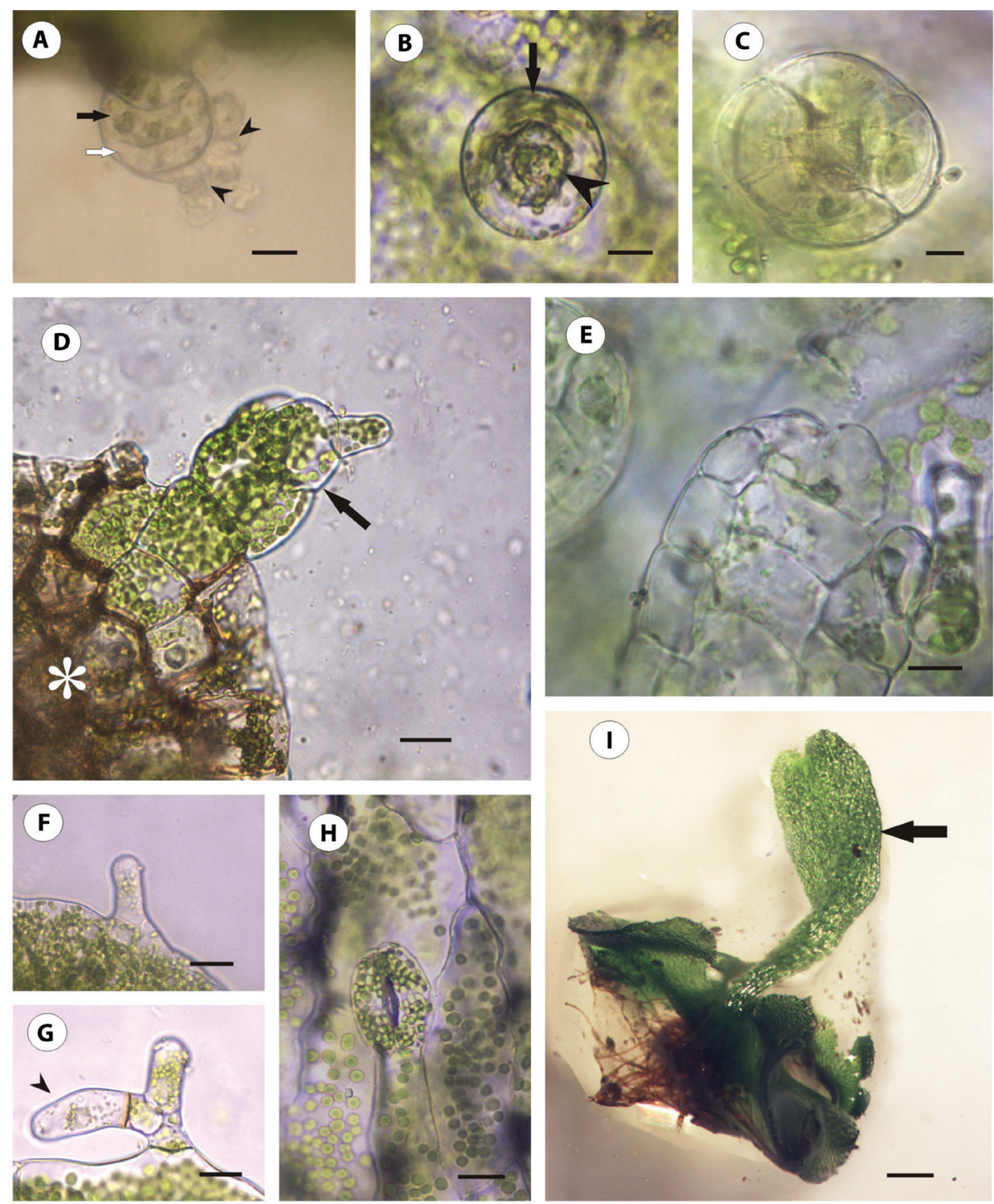

Fig. 4. Gametangios y esporofito de M. mortoniana. (A) Anteridio, compuesto por una célula basal (flecha negra) y célula anular (flecha blanca) y anterozoides (cabeza de flecha). (B) Anteridio con su célula anular (flecha) y opérculo (cabeza de flecha). (C) Arquegonio con sus 4 hileras de células. (D) Yema en desarrollo (flecha) con tejido circundante del gametofito necrosado (asterisco). (E) Arquegonio, cada hilera con 5 células. (F) Pelo unicelular glandular del esporofito. (G) Pelo tricelular bifurcado del esporofito (cabeza de flecha). (H) Estoma anomocítico del esporofito. (I) Primera hoja del esporofito (flecha) y restos del gametofito. Escala de las barras: A: $15 \mu \mathrm{m} ; \mathbf{B}: 10 \mu \mathrm{m} ; \mathbf{C}: 5 \mu \mathrm{m}$; D: $30 \mu \mathrm{m}$; E: $5 \mu \mathrm{m} ; \mathbf{F}: 15 \mu \mathrm{m}$; G-H: $20 \mu \mathrm{m}$; I: $250 \mu \mathrm{m}$.

Fig. 4. Gametangia and sporophyte of M. mortoniana. (A) Anteridium, composed of a basal cell (black arrow) and annular cell (white arrow) and antherozoids (arrowhead). (B) Anteridium with its annular cell (arrow) and operculum (arrowhead). (C) Archegonium with its 4 rows of cells. (D) Developing bud (arrow) with surrounding necrotic gametophyte tissue (asterisk). (E) Archegonium, each row with 5 cells. (F) Glandular unicellular sporophyte hair. (G) Forked tricellular sporophyte hair (arrowhead). (H) Anomocitic stoma of the sporophyte. (I) First leaf of the sporophyte (arrow) and remains of the gametophyte. Scale bars: A: $15 \mu \mathrm{m}$; B: $10 \mu \mathrm{m}$; C: $5 \mu \mathrm{m}$; D: $30 \mu \mathrm{m}$; E: $5 \mu \mathrm{m}$; F: $15 \mu \mathrm{m}$; G-H: $20 \mu \mathrm{m} ; \mathbf{I}: 250 \mu \mathrm{m}$. 
tipo-escama ubicadas principalmente en los márgenes del gametofito. En estadíos tempranos del desarrollo presentaron pocas células de ancho, escasos cloroplastos y una cabezuela glandular apical (Fig. 5E). Posteriormente, se ensancharon (Fig. 5F) y su desarrollo culminó con el engrosamiento de las paredes radiales, volviéndose clatradas, con margen dentado y conservando la cabezuela glandular (Fig. 5G), a medida que envejecían las escamas se curvaban.

Gametangios: Los anteridios en M. mortoniana surgieron a los 40 días (Fig. 4A y Fig. 4B) y en P. macrocarpa a los 230 días (Fig. 5B y Fig. 5C); en ambos casos fueron globosos, se ubican en la cara ventral cerca de los rizoides y con tres células, la basal, la anular y la opercular. Los arquegonios en M. mortoniana, aparecieron a los 45 días de la germinación (Fig. 4C y Fig. 4E), mientras que en P. macrocarpa fue a los 70 días (Fig. 5A y Fig. 5D); en ambos casos se ubicaron en la cara ventral del gametofito, pero cercanos a la escotadura, con el cuello recto a ligeramente curvado y están formados por cuatro hileras de células cada una de cuatro a seis células de longitud. En el caso de M. mortoniana los gametofitos fueron bisexuales y los anteridios surgieron inicialmente. Los gametofitos en P. macrocarpa fueron tanto unisexuales como bisexuales; los femeninos surgieron inicialmente, posteriormente los masculinos y por último, después de los 270 días de la germinación, los bisexuales.

Esporofitos: En M. mortoniana (Fig. 4I) surgió a los 120 días, con una lámina simple y espatulada, con pelos unicelulares capitados (Fig. 4F) y tricelulares bifurcados (Fig. 4G). Los estomas se ubicaron en la cara abaxial y fueron del tipo anomocítico (Fig. 4H). En $P$. macrocarpa creció después de los 500 días (Fig. $5 \mathrm{H}$ ), presentó una lámina simple y espatulada, con pelos unicelulares y pluricelulares ramificados en ambas caras, especialmente la abaxial (Fig. 5I). Los estomas fueron similares a los de M. mortoniana.

\section{DISCUSIÓN}

Un carácter importante que comparten las especies de la familia, incluidos los géneros Pleopeltis y Microgramma, es el de las esporas, las cuales son amarillentas, monoletes y elipsoidales en vista polar (Moran, 2004). El material analizado de $P$. macrocarpa presentó esporas con características morfológicas similares a las descritas por Tryon \& Lugardon (1992). El tamaño de las esporas fue menor de $15-20 \mu \mathrm{m}$ de diámetro polar y diámetro ecuatorial, respectivamente, en comparación a las medidas presentadas por Giudice, Morbelli, Piñeiro, Copello, \& Erra (2004). Dichos autores analizaron material acetolizado del noroeste argentino, en este trabajo, las esporas fueron analizadas en estado natural por lo que las diferencias de tamaño puede ser un carácter importante para considerar en próximos estudios.

De acuerdo con Arroyo-Alfaro, PeláezPeláez \& Rodríguez-Rodríguez (2007) las esporas de $M$. percussa tardaron entre 20 y 25 días en germinar, las esporas de M. lycopodioides (L.) Copel. y M. piloselloides (L.) Copel. entre los siete y diez días (Mendoza-Ruiz \& Pérez-García, 2005), en este trabajo, las esporas de M. mortoniana tardaron 20 días. En el caso de $P$. macrocarpa, la germinación de esporas de especies mexicanas fue analizada por Reyes-Jaramillo, Pérez-García, \& MendozaRuiz (2003), estos autores hallaron que ocurre entre los siete y los 24 días, siendo la especie que más demora $P$. macrocarpa debido a que tarda 13-24 días. Sin embargo, los resultados del cultivo in vitro en este trabajo indican que P. macrocarpa demora seis a ocho días. Estas diferencias podrían deberse a la composición del medio de cultivo, temperatura, luminosidad y humedad; factores que deberían tenerse en cuenta en próximos estudios.

Las especies bajo estudio presentaron el patrón de germinación tipo Vittaria, coincidiendo con los resultados mencionados por Arroyo-Alfaro, Peláez-Peláez \& RodríguezRodríguez (2007) para las especies mexicanas de Microgramma y la mayoría de las especies de Pleopeltis incluida P. macrocarpa. El 



Fig. 5. Gametangios y esporofito de P. macrocarpa. (A) Arquegonio con el cuello curvo. (B) Anteridio con anterozoides (cabeza de flecha). (C) Anteridio compuesto por una célula basal (flecha blanca), una célula anular (flecha negra) y el opérculo (cabeza de flecha). (D) Cuello de los arquegonios con sus cuatro hileras de células. (E) Escamas en formación con cabezuela glandular apical (cabeza de flecha). (F) Detalle de escama con cabezuela glandular apical (cabeza de flecha). (G) Escama clatrada completamente desarrollada, con margen dentado y cabezuela glandular apical (cabeza de flecha). (H) Primera hoja del esporofito (flecha) y restos del gametofito. (I) Pelos pluricelulares ramificados del esporofito. Escala de las barras: A: $20 \mu \mathrm{m}$; B-C: $10 \mu \mathrm{m}$; D: $20 \mu \mathrm{m}$; E: $100 \mu \mathrm{m}$; F: $80 \mu \mathrm{m} ; \mathbf{G}: 50 \mu \mathrm{m} ; \mathbf{H}: 1 \mathrm{~mm} ; \mathbf{I}: 30 \mu \mathrm{m}$.

Fig. 5. Gametangia and sporophyte of P. macrocarpa. (A) Archegonian with curved neck. (B) Antheridium with antherozoids (arrowhead). (C) Antheridium composed of a basal cell (white arrow), annular cell (black arrow) and the operculum (arrowhead). (D) Neck of archegonians with their four rows of cells. (E) Scales in formation with apical glandular head (arrowhead). (F) Scale detail with apical glandular head (arrowhead). (G) Fully developed clathrate scale with toothed margin and apical glandular head (arrowhead). (H) First sporophyte leaf (arrow) and gametophyte remains. (I) Branched multicellular sporophyte hair. Scale bars: A: $20 \mu \mathrm{m}$; B-C: $10 \mu \mathrm{m}$; D: $20 \mu \mathrm{m}$; E: $100 \mu \mathrm{m}$; F: $80 \mu \mathrm{m}$; G: $50 \mu \mathrm{m}$; H: $1 \mathrm{~mm}$; I: $30 \mu \mathrm{m}$. 
desarrollo del gametofito correspondió al tipo Drynaria en ambas especies. Dicho patrón coincide con lo mencionado por otros autores (Nayar \& Kaur, 1971; Chiou \& Farrar, 1997a). Sin embargo, en la familia puede presentarse más de un tipo de desarrollo protálico como Kaulinia (Nayar \& Kaur, 1971), Aspidium (Arroyo-Alfaro et al., 2007), Ceratopteris y Adiantum (Chiou \& Farrar, 1997b).

En cuanto al color de los rizoides ReyesJaramillo \& Pérez-García (1994) afirman que en Polypodium lepidotrichum (Fée) Maxon son de color pardo claro, Arroyo-Alfaro, PeláezPeláez \& Rodríguez-Rodríguez (2007) indican que en $M$. percussa son pardo hialinos, Vázquez-Pérez, Mendoza-Ruiz \& Pérez-García (2012) estudiaron siete taxa epífitos mexicanos de Polypodium con rizoides hialinos o de color pardo claro. Por su parte, Reyes-Jaramillo, Pérez-García \& Mendoza-Ruiz (2003) mencionan que en las especies mexicanas de Pleopeltis son de color hialino a pardo claro. En este trabajo el color de los rizoides de ambas especies fue pardo oscuro.

De acuerdo con Atkinson \& Stokey (1964) los tricomas de los gametofitos no tendrían valor taxonómico debido a que en ciertas ocasiones son útiles para la identificación de taxones y en otras no. Sin embargo, Huang et al. (2015) afirman que el carácter más estable en las Polypodiaceae son los pelos unicelulares capitados en los márgenes y esparcidos en el gametofito. Mendoza-Ruiz \& Pérez-García (2005) agregan que la presencia de un glóbulo lipídico en la primera célula protálica es otro carácter que puede considerarse como diagnóstico para este grupo.

La morfología de las primeras hojas del esporofito de $M$. mortoniana coincide con lo mencionado por Mendoza-Ruiz \& PérezGarcía (2005). Sin embargo, estos autores mencionan estomas polocíticos, en este estudio se observaron estomas anomocíticos (Van Cotthem, 1973). Los gametofitos de las especies epífitas a menudo se encuentran dentro de densos cojines de musgos, donde la interacción entre gametofitos puede verse significativamente obstaculizada (Dassler \& Farrar, 2001).
Por otro lado, ésta alta densidad de musgos pueden mantener el agua disponible durante períodos muy largos y así ayudar en la fertilización. Varios autores han reconocido dentro de estas estrategias utilizadas por los gametofitos de helechos epífitos, la capacidad de desarrollar yemas como modo de reproducción asexual y la capacidad de aumentar la longevidad de los mismos (Granados-Sánchez, LópezRíos, Hernández-García, \& Sánchez-González, 2003; Watkins Jr. \& Cardelús, 2012). En el presente trabajo se observa que M. mortoniana desarrolla yemas después de la formación de los anteridios mientras que $P$. macrocarpa no lo hace. Así podríamos inferir que el desarrollo de las yemas en $M$. mortoniana le permitiría propagarse fácilmente en diferentes sustratos, tal como se observa en el campo.

La capacidad de formar yemas que derivan en gametofitos masculinos tendría relación con la formación de anteridiógenos (Näf, 1979). El anteridiógeno también puede inducir que las esporas previamente enterradas germinen y den lugar a nuevos gametofitos (Voeller, 1971). La variación en el hábito de crecimiento, incluido el crecimiento indeterminado, la ramificación y la producción de yemas pueden influir en el comportamiento reproductivo al aumentar la probabilidad de interacción entre gametofitos distantes y entre gametofitos establecidos en diferentes momentos, además de beneficiarse con la propagación a nuevos micrositios (Chiou \& Farrar, 1997b; Dassler \& Farrar, 2001).

Otras adaptaciones que pueden estar relacionadas con el hábito epífito es la formación de pelos y escamas. Stokey (1960) observó gametofitos de seis meses con pelos ramificados y escamas clatradas en Aglaomorpha y Microsorium. En este estudio los gametofitos de $P$. macrocarpa presentaron tricomas tipo escamas clatradas a los cuatro meses de siembra, similar a lo observado por Nayar (1962). Los tricomas tipo escama podrían favorecer la incidencia de la luz sobre los gametofitos desarrollados en ambientes más sombríos y prevenir la deshidratación foliar.

Ramos Giacosa, Giudice, Pipo, \& Luna (2014) plantean que una estrategia para la 
conservación de las especies vegetales constituye el cultivo en laboratorio, aclimatación y posterior reintroducción en los ambientes naturales. Así, actividades de conservación ex situ que incluyen cultivo in vitro permiten conocer las diferentes etapas del desarrollo protálico. Esto podría aportar información valiosa en estudios sistemáticos y filogenéticos y ayudar en la conservación de la flora nativa de la región. De esta forma, estudios en germinación de esporas, desarrollo de gametofitos y cultivo de esporofitos constituyen la base de programas de recuperación para las poblaciones naturales dañadas (Ibars \& Estrelles, 2012). Los esporofitos obtenidos de M. mortoniana y P. macrocarpa presentan un crecimiento más lento con respecto a los de especies terrestres y aún se encuentran en etapa de aclimatación. Una vez finalizada esta etapa serán reintroducidos en la reserva para reforzar las poblaciones y colaborar en su conservación.

Finalmente, la demora en la formación de esporofitos, principalmente en $P$. macrocarpa, a través de la reproducción sexual, permite inferir que el éxito de su propagación in situ estaría sujeto a la reproducción vegetativa a través de rizomas rastreros. En el caso de $M$. mortoniana su amplio desarrollo sobre diversos sustratos estaría favorecido por la producción de yemas, como estrategia de reproducción vegetativa. La presencia de un glóbulo lipídico en la primera célula protálica así como la formación de pelos unicelulares capitados en el margen y en el resto de la lámina del gametofito son caracteres que podrían ser considerados en la sistemática del grupo.

\section{AGRADECIMIENTOS}

Al personal de la Reserva Natural Punta Lara y al financiamiento de la Universidad Nacional de La Plata (N 725).

\section{RESUMEN}

Pleopeltis macrocarpa y Microgramma mortoniana son dos helechos epífitos de la familia Polypodiaceae hallados con baja frecuencia en la Reserva Natural Punta
Lara (Buenos Aires, Argentina). El objetivo de este trabajo fue estudiar la morfogénesis de gametófitos epífitos para fortalecer poblaciones vulnerables y contribuir a su conservación. Se recolectaron hojas fértiles. Las esporas se sembraron en placas de Petri con medio de cultivo Dyer. Las esporas se caracterizaron por ser monoletes, elipsoidales, amarillentas y con ornamentación verrucosa. La germinación fue del tipo Vittaria y el desarrollo del gametofito es del tipo Drynaria. El esporofito de P. macrocarpa surgió a los 500 días y el de M. mortoniana a los 120. El patrón de germinación, el desarrollo del gametofito, el glóbulo lipídico en la célula protálica y los pelos unicelulares capitados en el margen podrían considerarse en la sistemática del grupo. La demora en la formación de esporofitos a través de la reproducción sexual, permite inferir que el éxito de su propagación estaría sujeto a la reproducción vegetativa.

Palabras clave: cultivo in vitro; desarrollo; epífitos; gametofito; helechos; propagación.

\section{REFERENCIAS}

Arroyo-Alfaro, S. J., Peláez-Peláez, F., \& RodríguezRodríguez, E. F. (2007). Avances en el desarrollo de la fase gametofítica de Microgramma percussa (Polypodiaceae). Arnaldoa, 14(1), 07-14.

Atkinson, L. R., \& Stokey, A. G. (1964). Comparative morphology of the gametophyte of homosporous ferns. Phytomorphology, 14, 51-70.

Barbetti, C. (2008). La Reserva Natural Punta Lara: área núcleo de la Reserva de la Biósfera Pereyra Iraola. Bases para una representación integrada en el espacio costero del Río de La Plata. Memoria Académica. Recuperado de http://www.fuentesmemoria.fahce. unlp.edu.ar/trab_eventos/ev.806/ev.806.pdf

Cabrera, A. L. (1976). Regiones fitogeográficas argentinas. Enciclopedia Argentina de Agricultura y Jardinería. Buenos Aires, Argentina: Acme.

Cacharini, D., \& Martínez, O. G. (2016a). Microgramma. En F. O. Zuloaga \& M. J. Belgrano (Eds.), Flora Vascular de la República Argentina. Licofitas, Helechos, Gymnospermae (Vol. 2, pp. 245-247). Buenos Aires, Argentina: Estudio Sigma.

Cacharini, D., \& Martínez, O. G. (2016b). Pleopeltis. En F. O. Zuloaga \& M. J. Belgrano (Eds), Flora Vascular de la República Argentina. Licofitas, Helechos, Gymnospermae (Vol. 2, pp. 260-266). Buenos Aires, Argentina: Estudio Sigma.

Chiou, W. L., \& Farrar, D. R. (1997a). Antheridiogen production and response in Polypodiaceae species. American Journal of Botany, 84, 633-640.

Chiou, W. L., \& Farrar, D. R. (1997b). Comparative gametophyte morphology of selected species of the 
family Polypodiaceae. American Fern Journal, 87(3), $77-86$.

Dassler, C. L., \& Farrar, D. R. (2001). Significance of gametophyte form in long-distance colonization by tropical, epiphytic ferns. Brittonia, 53, 352-369.

Dyer, A. F. (1979). The culture of fern gametophytes for experimental investigation. In A. F. Dyer (Ed.), The experimental biology of ferns (pp. 253-305). London, United Kingdom and New York, United States: Academic Press.

Giudice, G. E., Morbelli, M. A., Piñeiro, M. R., Copello, M., \& Erra, G. (2004). Spore morphology of the Polypodiaceae from Northwestern Argentina. American Fern Journal, 94(1), 9-27.

Giudice, G. E., Ramos Giacosa, J. P., Luna, M. L., Yáñez, A., \& de la Sota, E. R. (2011a). Diversidad de helechos y licofitas de la Reserva Natural Punta Lara, Buenos Aires, Argentina. Revista de Biología Tropical, 59(3), 1037-1046.

Giudice, G. E., Ramos Giacosa, J. P., Luna, M. L., Macluf, C., Ponce, M., Márquez, G., \& de la Sota, E. (2011b). Evaluación preliminar del grado de amenaza de los helechos y licofitas de Argentina. Boletín de la Sociedad Argentina de Botánica, 46(1-2), 151-161.

Granados-Sánchez, D., López-Ríos, G. F., HernándezGarcía, M. Á., \& Sánchez-González, A. (2003). Ecología de las plantas epífitas. Revista Chapingo Serie Ciencias Forestales y del Ambiente, 9(2), 101-111.

Huang, Y. M., Amoroso, V. B., Coritico, F. P., Ko, C. W., Kao, T. T., Callado, J. R., \& Chiou, W. L. (2015). Reproductive biology of Aglaomorpha cornucopia (Copel.) M. C. Roos, a rare and endemic fern from the Philippines. American Fern Journal, 105(1), 31-44.

Ibars, A. M., \& Estrelles, E. (2012). Recent developments in Ex Situ and In Situ conservation of ferns. Fern Gazette, 19(3), 67-86.

Luna, M. L., Yáñez, A., Ramos Giacosa, J. P., Gorrer, D. A., Berrueta, P. C., \& Giudice, G. E. (2016). In vitro spore culture and reproductive aspects of the anual fern Annogramma chaerophylla (Pteridaceae). Boletín de la Sociedad Argentina de Botánica, 51(4), 675-682.

Mendoza-Ruiz, A., \& Pérez-García, B. (2005). Análisis comparativo de la fase sexual de dos especies de Microgramma (Polypodiaceae, Pleopeltoideae). Acta Botánica Mexicana, 71, 1-10.

Moran, R. C. (2004). Natural history of ferns. Cambridge, United Kingdom: Timber Press.

Näf, U. (1979). Antheridiogens and antheridia development. In A. F. Dyer (Ed.), The experimental biology of ferns (pp. 435-470). London, United Kingdom: Academic Press.
Nayar, B. K. (1962). Morphology of spores and prothalli of some species of Polypodiaceae. Botanical Gazette, 123(3), 223-232.

Nayar, B. K., \& Kaur, S. (1971). Gametophytes of homosporous ferns. The Botanical Review, 37, 295-396.

Ramos Giacosa, J. P., Giudice, G. E., Pipo, L., \& Luna, M. L. (2014). Morfología de las esporas, desarrollo gametofítico y conservación de Thelypteris abbiattii y T. hispidula (Thelypteridaceae) de la Reserva Natural Punta Lara, Buenos aires. Boletín de la Sociedad Argentina de Botánica, 49(2), 217-226.

Ramos Giacosa, J. P., Gorrer, D. A., Giudice, G. E., \& Luna, M. L. (2017). Gametophyte development and conservation of Ctenitis submarginalis (Dryopteridaceae) in Buenos Aires Province, Argentina. Boletín de la Sociedad Argentina de Botánica, 52(4), 33-40.

Reyes-Jaramillo, I., \& Pérez-García, B. (1994). Morfología y estrategias reproductivas del gametofito de Polypodium lepidotrichum (Fee) Maxon (Polypodiaceae). Acta Botánica Mexicana, 28, 71-78.

Reyes-Jaramillo, I., Pérez-García, B., \& Mendoza-Ruiz, A. (2003). Morfogénesis de los gametofitos de especies mexicanas de Pleopeltis (Polypodiaceae, subfamilia Pleopeltoideae). Revista de Biología Tropical, 51(2), 321-332.

Stokey, A. G. (1960). Multicellular and branched hairs on the fern gametophyte. American Fern Journal, $50(1), 78-87$.

Tryon, A. F., \& Lugardon, B. (1992). Spores of the Pteridophyta. New York, United States: Springer-Verlag.

Van Cotthem, J. W. R. (1973). Stomatal types and systematics. In A. C. Jermy, J. A. Crabbe, \& B. A. Thomas (Eds.), The phylogeny and classification of ferns (pp. 57-71). New York, United States: Academic.

Vázquez-Pérez, N., Mendoza-Ruiz, A., \& Pérez-García, B. (2012). Morfogénesis de la fase sexual de siete taxa epífitos de Polypodium (Polypodiaceae) de México. Acta Botánica Mexicana, 98, 5-21.

Voeller, B. (1971). Developmental physiology of fern gametophytes: relevance for biology. BioScience, 21, 267-270.

Watkins Jr, J. E., \& Cardelús, C. L. (2012). Ferns in an angiosperm world: cretaceous radiation into the epiphytic niche and diversification on the forest floor. International Journal of Plant Sciences, 173(6), 695-710.

Zuloaga, F. O., \& Belgrano, M. J. (2016). Flora Vascular de la República Argentina. Vol. 2, Licofitas, Helechos, Gymnospermae. Buenos Aires, Argentina: Estudio Sigma. 